\title{
Factors Inhabiting ICTs Usage among Farmers: Comparative Analysis from Pakistan and China
}

\author{
Muhammad Yaseen ${ }^{1,2}$, Shiwei Xu1 ${ }^{*}$, Wen Yu1, Muhammad Luqman1,2, Sadia Hassan33, \\ Muhammad Ameen ${ }^{4}$ \\ ${ }^{1}$ Agricultural Information Institute, Chinese Academy of Agricultural Sciences, Beijing, China \\ ${ }^{2}$ Department of Agricultural Extension \& Rural Development, University College of Agriculture, University of \\ Sargodha, Sargodha, Pakistan \\ ${ }^{3}$ Graduate School of Chinese Academy of Agricultural Sciences, Beijing, China \\ ${ }^{4}$ Department of Agricultural Engineering, Pir Mehr Ali Shah Arid Agriculture University, Rawalpindi, Pakistan \\ Email: *xushiwei@caas.cn, yaseen99pk@hotmail.com,yuwen@caas.cn,muhammadluqman_uos@yahoo.com, \\ sadiahassan140@yahoo.com, ameenkhan114@yahoo.com
}

Received 4 May 2016; accepted 28 May 2016; published 31 May 2016

Copyright (C) 2016 by authors and Scientific Research Publishing Inc.

This work is licensed under the Creative Commons Attribution International License (CC BY). http://creativecommons.org/licenses/by/4.0/

(c) (i) Open Access

\section{Abstract}

The current study aimed to provide comparative analysis between Pakistan and China regarding factors inhabiting ICTs usage by farmers. Population of this study contained two categories. Firstly, the population was comprised of Punjab province of Pakistan selected purposively. Secondly, population comprises of Hebei province of China selected purposively as the study province. For this purpose 160 respondents were selected from eight villages of Punjab province in Pakistan and 122 respondents were selected from six villages of Hebei province in China. The results revealed that there is significant influence of socio-economic characteristics like age, education, and income and sources of farmers in Pakistan with compare to China. In case of Pakistan information and communication technologies used by farming community are in the form of telephone (6.25\%), mobile $(100 \%)$, computer $(38.12 \%)$, internet $(11.88 \%)$, TV $(80.63 \%)$, radio $(10.63 \%)$ and newspaper (7.5\%) while in case of China rural farmers are using telephone $(18.03 \%)$, mobile (99.18\%), computer $(29.51 \%)$, internet $(17.21 \%)$, TV $(99.18 \%)$, radio $(9.02 \%)$ and newspaper (3.28\%) of farmers have no opinion. Keeping in view the results the government of Pakistan should concentrate on efficient use of computer and internet. Similarly, government of China should also concentrate on best use of computer and internet towards adoption of advanced technologies.

${ }^{*}$ Corresponding author.

How to cite this paper: Yaseen, M., Xu, S.W., Yu, W., Luqman, M., Hassan, S. and Ameen, M. (2016) Factors Inhabiting ICTs Usage among Farmers: Comparative Analysis from Pakistan and China. Open Journal of Social Sciences, 4, 287-294. 


\section{Keywords}

\section{Comparision, Factors, China, Pakistan, ICT}

\section{Introduction}

Use of Information and Communication Technologies (ICTs) in an innovative way for development of agriculture sector which is the most vital part of economy in most of the developing countries. This sector claims to be important being ensures poverty reduction and food security and is responsible for the provision of sustainable livelihoods [1]. With the advancement in communication technologies and its mechanism, extension and rural advisory services are going to be more reliant on ICTs as to be flourishing in more efficient, appropriate and innovative ways for delivery of agro-based advanced technologies to the end-users. Moreover, ICT based extension and advisory services play a vital role in provision of agricultural information and knowledge for farmers. Keeping in view the significance of ICTs in overall agricultural advancement, it is necessary to promote ICT based agricultural information dissemination to enhance agricultural productivity on one hand and also to provide sustainable agricultural information delivery mechanism [2].

Adopting ICTs as source of agricultural information is a very complex and critical procedure. It involves various steps and factors at farmer's level. Out of these factors, socio-economic profile of farmers placed a prominent position as in adoption process key role is their socio-economics. Various studies have been conducted to investigate socio-economic factors influencing behavior of farming community with regard to ICT based agricultural extension services, approaches and other social activities. Diversified demographic attributes have been supposed to be manipulated by intellectual and social and economic variation associated with behavior [3]. These factors may also be proficient for different policies to promote acceptance of ICT oriented agronomic practices among farmers for support in improving farm productivity and sustainability in agriculture [4]. In contrary to this, it has also been found that there is significant association between some demographics of farmers like age and education of farmers and their development or advancement in their technological information [5]. The relationship between educational profile of farmers with their advancement in ICTs adoption and usage was also presented by Atibioke et al. [6].

With similar notion Arfan, et al. (2015) reported that some demographics of farmers like education, size of farm and income demonstrates a most significant positive linkages with the enhanced knowledge level of the farming community [7]. It was also investigated that the demographic characters should be concentrated to acquire maximum productivity of resources developed for the enhancement of agricultural information and knowledge of the farming community. Likewise, [8] it was also observed that majority (70.1\%) of extension staff were men, having almost eleven years working experience and aged more than 40 years. Furthermore, statistical variation was found which indicates that the farmer's age, education, experience and gender, were considerably related with the benefits perceived by farmers. Some outcomes also exposed that socio-economic factors of youth including young males and females have better information related to profits by agro-based farms [9]. There is a momentous relation between gender and farming scientific implementation [6].

So in the light of above situation the present study was designed to investigate different factors like age, education, size of land holding, family size, professions or occupations etc. which have influence on farmers' behavior to adopt information commutation technologies in agriculture [10]. The present study is comparative analysis of developing country like Pakistan with most emerging economies the People Republic of China. This study provides guidelines for other developing countries including Pakistan to initiate strategies and policies for ICT oriented agricultural information packages for farming community to equip them with latest agricultural knowledge to apply at their farms for sustainable agriculture and rural development.

\section{Data and Methodology}

\subsection{Description of Data}

The results presented in Table 1 revealed that 55\% of farmers from Pakistan have age more than 50 years while $45 \%$ have age equal or less than 50 years while in case of China $32.79 \%$ of farmers have more than 50 years age 
Table 1. Demographic attribute of farmers in Pakistan and China.

\begin{tabular}{|c|c|c|c|c|}
\hline \multirow{2}{*}{ Attributes } & \multicolumn{2}{|c|}{ Pakistan } & \multicolumn{2}{|c|}{ China } \\
\hline & Frequency & Percentage & Frequency & Percentage \\
\hline \multicolumn{5}{|l|}{ Age in years } \\
\hline$\geq 50$ & 72 & $45 \%$ & 82 & $67.21 \%$ \\
\hline$<50$ & 88 & $55 \%$ & 40 & $32.79 \%$ \\
\hline \multicolumn{5}{|c|}{ Education (schooling years) } \\
\hline$\geq 10$ & 90 & $56.3 \%$ & 12 & $09.84 \%$ \\
\hline$<10$ & 70 & $43.8 \%$ & 110 & $90.16 \%$ \\
\hline \multicolumn{5}{|l|}{ Family size } \\
\hline$\geq 5$ & 133 & $83.1 \%$ & 32 & $26.2 \%$ \\
\hline$<5$ & 27 & $16.9 \%$ & 90 & $73.8 \%$ \\
\hline \multicolumn{5}{|l|}{ Land holding } \\
\hline$\geq 12$ & 65 & $41 \%$ & 1 & $0.82 \%$ \\
\hline$<12$ & 95 & $59 \%$ & 121 & $99.18 \%$ \\
\hline \multicolumn{5}{|l|}{ Occupation } \\
\hline Farming & 144 & $90 \%$ & 104 & $85.25 \%$ \\
\hline Business & 1 & $0.6 \%$ & 0 & $0.00 \%$ \\
\hline Govt. job & 12 & $7.5 \%$ & 2 & $01.64 \%$ \\
\hline Off-farm job & 3 & $1.9 \%$ & 16 & $13.11 \%$ \\
\hline
\end{tabular}

and majority (67.21\%) of farmers have age equal or less than 50 years. Education level of farmers in Pakistan is $56.3 \%$ and $43.8 \%$ for 10 or less schooling years and above 10 years of schooling respectively. In China $9.84 \%$ and $90.16 \%$ farmers have less or 10 and above 10 schooling years of education. Majority of farmers’ (83.1\%) have family size of 5 or less number of persons and some (16.9\%) of farmers' have family size above 5 number of individuals. While in China only $26.2 \%$ of farmers' have family members of 5 or less while, $73.8 \%$ of farmers have family size of more than 5 individuals.

Similarly, land holding size for farmers in Pakistan is equal or less than 12 acres for $41 \%$ farmers and more than 12 acres for 59\% farmers, in China more than 99\% farmers have above 12 acres land size and only less than $1 \%$ have equal or less than 12 acres land size. As for as occupation or profession of farming community is concerned in case of Pakistan overwhelming majority (90\%) of farmers have farming occupation while business, government job and off-farm job are occupation of $0.6 \%, 7.5 \%$ and $1.9 \%$ of farmers respectively. While in case of China majority (85.25\%) of farmers has farming occupation, $1.64 \%$ and $13.11 \%$ farmers have government job and off-farm jobs respectively although no one has business as occupation in China.

According to results indicated in Table 2, in Pakistan only 6.25\% of farmers are utilizing landline telephone while all of the respondents are using mobile phone for the sake of agricultural information, similarly computer, internet, TV, radio and newspaper is used by 38.12\%, $11.88 \%, 80.63 \%, 10.63 \%$ and $7.50 \%$ respectively for the propose to get agricultural information. While in China, landline telephone is used by $18.03 \%$ of farmers and 99.18\% of farmers use mobile phone to get latest information related to agriculture. Computer, internet, TV, Radio and Newspapers are used by 17.21\%, 99.18\%, 9.02\% and 3.28\% respectively by the farmers with regard to obtain latest technology information related to agriculture.

\subsection{Population of Study}

As the present research was conducted in two countries i.e. Pakistan and China, therefore population of this 
Table 2. Information \& communication technologies application in Pakistan and China.

\begin{tabular}{|c|c|c|c|c|c|c|c|c|}
\hline \multirow{3}{*}{ Attributes } & \multicolumn{4}{|c|}{ Pakistan } & \multicolumn{4}{|c|}{ China } \\
\hline & \multicolumn{2}{|c|}{ Yes } & \multicolumn{2}{|c|}{ No } & \multicolumn{2}{|c|}{ Yes } & \multicolumn{2}{|c|}{ No } \\
\hline & Freq. & $\%$ & Freq. & $\%$ & Freq. & $\%$ & Freq. & $\%$ \\
\hline Telephone & 10 & 06.25 & 150 & 93.75 & 22 & 18.03 & 100 & 81.97 \\
\hline Mobile & 160 & 100 & 0 & 0 & 121 & 99.18 & 1 & 0.82 \\
\hline Computer & 61 & 38.12 & 99 & 61.88 & 36 & 29.51 & 86 & 70.49 \\
\hline Internet & 19 & 11.88 & 141 & 88.12 & 21 & 17.21 & 101 & 82.79 \\
\hline TV & 129 & 80.63 & 31 & 19.37 & 121 & 99.18 & 1 & 0.82 \\
\hline Radio & 17 & 10.63 & 143 & 89.36 & 11 & 9.02 & 111 & 90.98 \\
\hline Newspaper & 12 & 07.50 & 148 & 92.50 & 4 & 3.28 & 118 & 96.72 \\
\hline
\end{tabular}

study was consisted of two categories. The first category of the population was comprises of Punjab province of Pakistan which is the largest on the basis of population with a share of $54 \%$ of country's total population [11]. The selection of the Punjab province was based on purposive method. The province is also most industrialized province of Pakistan, containing manufacturing industries like textiles, electronic equipments, surgical appliances, metal, processed foods etc. It has arable land as greatest natural resource with $35.2 \%$ agricultural land [12]. Punjab has 36 districts and major crops of province includes wheat and cotton are major crops of the province other crops include; rice, sugarcane, maize, millet, pulses, oilseeds, vegetables and fruits. Agriculture is core of Punjab's economy, as it supplies nearly $68 \%$ in national grain produce annually. Cultivated land area of province is 51 million acres and above 9 million acres are in the cultivable waste form in various regions of province [13].

The $2^{\text {nd }}$ category of population comprises of Hebei province of China selected purposively as the study province, because of its locality extremely to north of Yellow River, is situated in north China and its climate is monsoon influenced with cold and dry winter, hot and humid summer. In 2014, GDP of Hebei was 2.942 trillion RMB, and ranked at 6 th in the country. Nearly $40 \%$ of labor force of province is directly involved in agricultural farming, forestry and livestock production. Major crops are wheat, maize, sorghum, millet, cotton, peanut, soybeans, sesame and fruits especially grapes. Total cultivated area of province is about 6.7 million hectares, producing 25 million tons farm produce annually. Hebei is famous for being major cotton producing province and given rise to a large-scale textile industry. Other industries including modern logistics, information technology, medicine, steel, petrochemical, office machinery and clothing industries are playing important role in development of provincial economy as well as boost up for country's economy [14]. All the farmers residing in Punjab province of Pakistan and Hebei Province of China are were considered as population of this study.

\subsection{Samples and Procedures for Sampling}

Multistage sampling design was adopted in this study. Out of the 36 districts of the Punjab four districts D. G. Khan, Faisalabad, Muzafargarh and Sargodha, from Punjab province were randomly selected and then from each district one tehsil were selected; two villages were selected from each tehsil based on simple random sampling technique. From each village 20 household farmers were selected again by using simple random sampling. Total samples of 160 household farmers were selected on random basis. Similarly, Hebei province was randomly selected from China after that Huailai County was selected randomly and then six villages were selected from Huailai County by using simple random techniques. Total sample of 122 household farmers were selected from 6 villages including; Dongshuiquan, Shimenwan, Anyingpu, Paoercun, Yanjiafang, and Zhanjiaying.

\subsection{Data Collection and Tool}

Household farmers are key stakeholder with regard to agricultural development; therefore, face-to-face interviews method was used with the help of validated and expert reviewed questionnaire. In order to get direct opi- 
nion and response of household farmers regarding different parameters included in present study. Questionnaire comprised of different sections like; demographic characteristics of household farmers, agricultural extension teaching methodologies, information \& communication technologies etc. Different experts related to agricultural extension, rural development, agricultural economics etc. from Pakistan and China reviewed the questionnaire to maintain validity of research instrument used. Questionnaire was translated into Chinese language to collect data from China; a team comprising professors and students of Agricultural Information Institute (AII) of Chinese Academy of Agricultural Sciences (CAAS) Beijing China has accomplished this task.

\subsection{Model Selection and Analysis}

Data analysis was carried out by using STATA software and applying logistic regression model for this study. Application of ICTs among farmers was measured as dichotomous, using value 1 for application of ICTs among farmer and 0 otherwise. Model specification for calculation is given below:

$$
C a_{p}=\alpha+\beta_{1} \text { age }+\beta_{2} e d u+\beta_{3} f_{-} \text {size }+\beta_{4} i f_{-} \text {farm }+\beta_{5} \text { land_area }+\beta_{6} \text { income }
$$

where $C a_{p}$ is probability of application of computer as ICTs in agriculture by farmers in Pakistan.

$$
C a_{c}=\alpha+\beta_{1} \text { age }+\beta_{2} e d u+\beta_{3} f_{-} \text {size }+\beta_{4} \text { if _ farm }+\beta_{5} \text { land_area }+\beta_{6} \text { income }
$$

where $C a_{c}$ is probability of application of computer as ICTs in agriculture by farmers in China.

$$
I a_{p}=\alpha+\beta_{1} \text { age }+\beta_{2} e d u+\beta_{3} f_{-} \text {size }+\beta_{4} \text { if _ farm }+\beta_{5} \text { land_area }+\beta_{6} \text { income }
$$

where $I a_{p}$ is probability of application of internet as ICTs in agriculture by farmers in Pakistan.

$$
I a_{c}=\alpha+\beta_{1} a g e+\beta_{2} e d u+\beta_{3} f_{-} \text {size }+\beta_{4} i f_{-} \text {farm }+\beta_{5} \text { land_area }+\beta_{6} \text { income }
$$

where $I a_{c}$ is probability of application of internet as ICTs in agriculture by farmers in China.

Listed in Table 3 are variables and their explanation which were used in the study.

\section{Results and Discussion}

The results presented in Table 4 indicate that in Pakistan education of household head is most significant with regard to adoption of computer as ICTs in agriculture because one unit increase in education level of household head will increase the odds of computer application by factor of 2.55. Similarly income and land area of household farmers has significant influence on computer application as ICTs, as one unit increase in income and land area of household will increase odds of computer application by factor of 0.999 and 1.096 respectively. While in case of China income and education of household head has most significant effect on computer application as ICTs tool as data shows that one unit increase in income and education of household head will increase odds of computer application by factor of 1.00 and 1.302 respectively.

The results shown in Table 5 indicate that in Pakistan farming occupation of household head has influence in

Table 3. variables used and their explanation.

\begin{tabular}{cl}
\hline Variable & Explanation \\
\hline if_com & Application of computer as ICT in agriculture by household head \\
if_int & Application of internet as ICT in agriculture by household head \\
age & Household head's (farmer) age \\
edu & Household head's (farmer) education \\
f_size & Household head's (farmer) family size \\
if_farm & Dummy variable; 1 = farming as source of income, $0=$ otherwise \\
land_area & Household head's total land holding \\
income & Annual income of household head \\
_cons & constant \\
\hline
\end{tabular}


Table 4. Factors effecting computer application by farmers in Pakistan \& China.

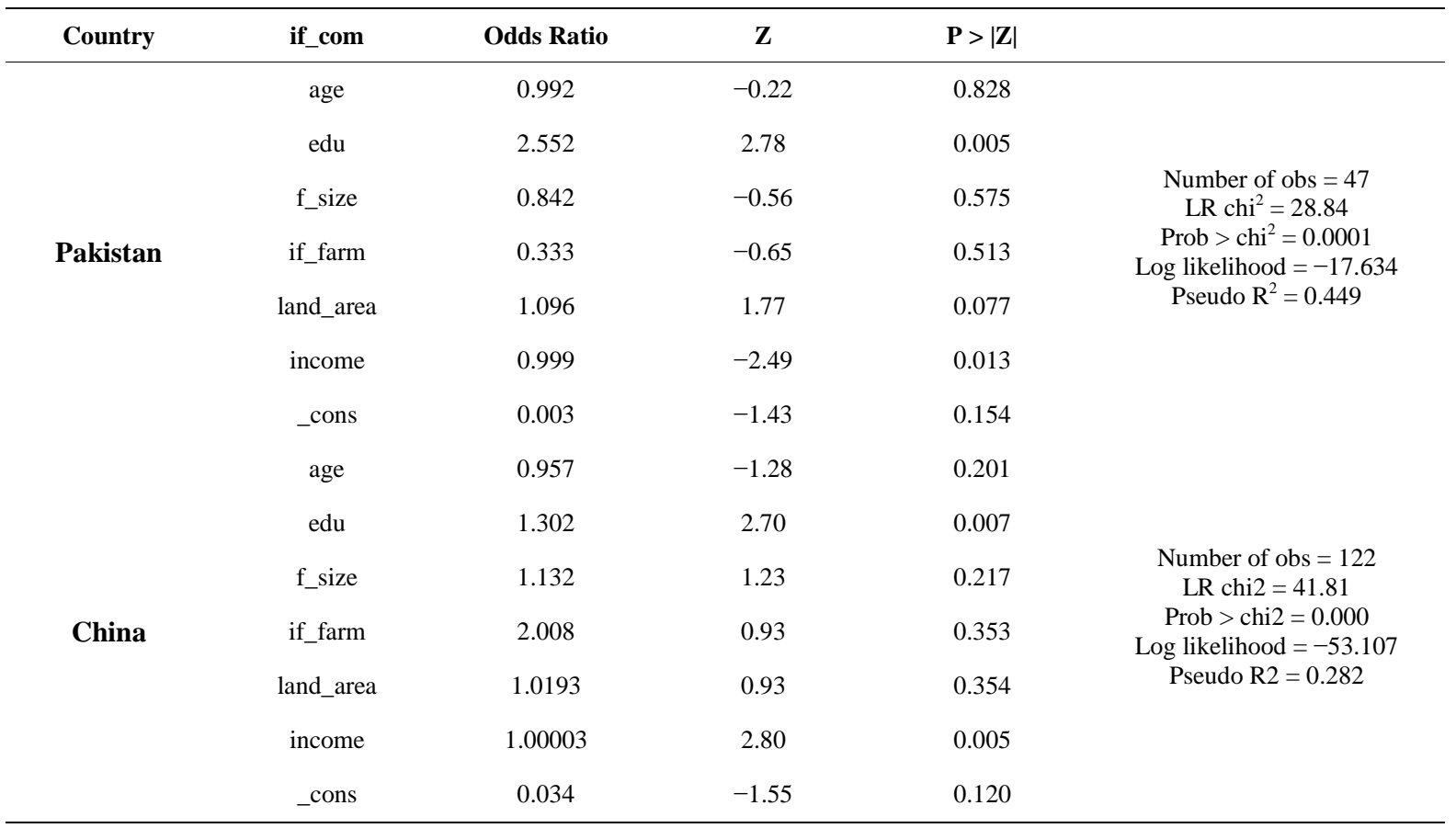

Table 5. Factors effecting internet application by farmers in Pakistan and China.

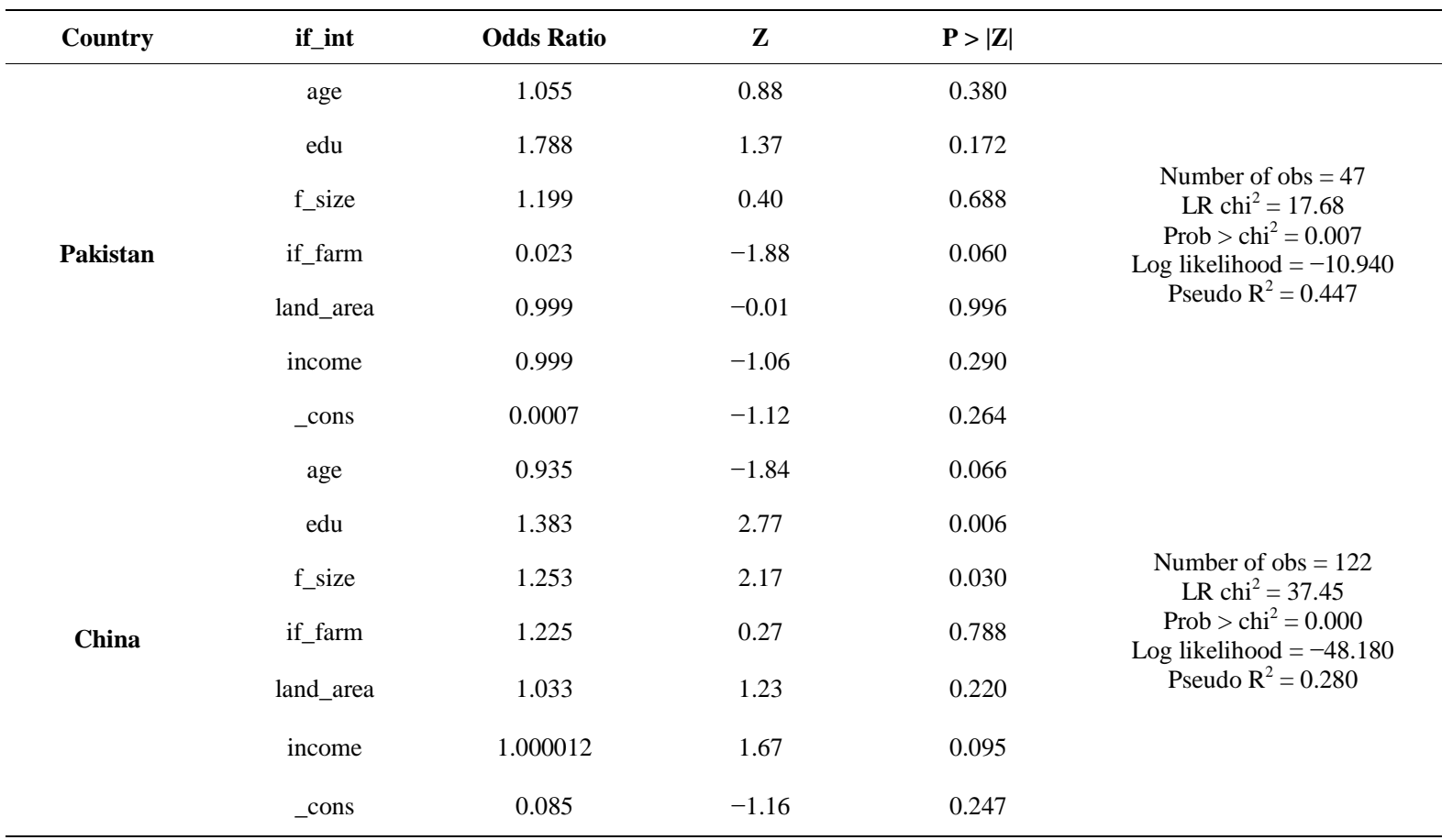

internet application by farming community as results present that one unit increase in farming occupation will increase odds of internet application by household head by factor of 0.023 . While this situation is quite different in China, as education of household head has most significant effect on internet application as ICTs tool that indicates one unit increase in education of household head will increase odds of internet application by factor of 1.383 . similarly, family size, age and income has also influence on internet application by household head, as results in 
Table 5 depicts that one unit increase in family size, age and income of household head it will increase odds of internet application as ICTs by factor of 1.253, 0.935 and 1.00 respectively.

\section{Conclusion \& Recommendations}

Education of household head has significant influence in adoption of computer as ICT tool application in agriculture in Pakistan and in China. Household head's income also manipulates computer application by household farmers in Pakistan as well as in China, with addition to influence of land area occupancy by household farmers in Pakistan. Likewise, usage of internet as ICT tool by household farmers in Pakistan is influenced by farming as occupation of household head. While in China household head's education has significant influence on internet usage. Similarly, family size, age and income of household head also influence internet application in agriculture.

On the basis of results following recommended are drawn for government of Pakistan and China:

1) Education is an import indicator for development, education level of farmer in Pakistan is not satisfactory, while this situation is encouraging in China but government should also increase educational level among farming community.

2) ICTs should be utilized in more innovative way, because farmers of both country (Pakistan \& China) are utilizing mobile phone almost $100 \%$, but there is need to maximize innovativeness in the use of ICTs so that farming community ensure food security, sustainable agriculture and livelihood.

3) Government of Pakistan should introduce some policies to boost up household income, land reform policies, and increasing involvement of youth in agriculture activities to ensure application of computer and internet in agriculture with goal to enhance agriculture productivity.

4) Similarly government of China should also ensure involvement of maximum family member in agricultural activities, encouraging youth as well as old aged in agriculture, and by increasing household income to improve application of computer and internet in agriculture to maximize crop productivity.

\section{Acknowledgements}

This study was supported by the program CAAS-ASTIP-2016-AII. The authors thanks for support from innovation fund founded by the Chinese Academy of Agricultural Sciences.

\section{References}

[1] Arfan, M., Ali S., Safdar, U. and Khan M.A.J. (2015) Study of Association between Demographic Characteristics and Increase in Knowledge of Farmers through Punjab Agricultural Helpline. Journal of Agricultural Research, 53, 287-294.

[2] Atibioke, O.A., Ogunlade, I., Abiodun, A.A., Ogundele, B.A., Omodara, M.A. and Ade A.R. (2012) Effects of Farmers' Demographic Factors on the Adoption of Grain Storage Technologies Developed by Nigerian Stored Products Research Institute (NSPRI): A Case Study of Selected villages in Ilorin West LGA of Kwara State. Research on Humanities and Social Sciences, 2, 56-63.

[3] Azilah, M.A., Foziah, J. and Ho, C.S. (2015) The Effects of Socio-Economic Influences on Households Recycling Behaviour in Iskandar Malaysia. ASEAN-Turkey ASLI (Annual Serial Landmark International) Conference on Quality of Life 2014, ABRA International Conference on Quality of Life, AQoL2014, 26-28 December 2014, Istanbul, Turkey. Procedia - Social and Behavioral Sciences, 202, 124-134.

[4] Burton, R.J.F. (2014) The Influence of Farmer Demographic Characteristics on Environmental Behavior: A Review. Journal of Environmental Management, 135, 19-26. http://dx.doi.org/10.1016/j.jenvman.2013.12.005

[5] CIA-Central Intelligence Agency (2016) the World Fact Book: South Asia, Pakistan. https://www.cia.gov/library/publications/the-world-factbook/geos/pk.html

[6] Gao, J., Barbieri, C. and Valdivia, C. (2014) A Socio-Demographic Examination of the Perceived Benefits of Agroforestry. Agroforestry Systems, 88, 301-309. http://dx.doi.org/10.1007/s10457-014-9683-8

[7] Government of the Pakistan (2015) Economics Survey 2014-15, Ministry of Finance and Economic Affairs, Government of Pakistan, Islamabad Pakistan.

[8] Government of the Punjab (2016) Budget: Agriculture Department Government of the Punjab, Pakistan. http://www.agripunjab.gov.pk/budget

[9] Govt. of the Hebei (2015) The People’s Government of Hebei Province. http://www.hebei.gov.cn/english/10718809/10719846/10721308/index.html 
[10] Landini, F. and Bianqui, V. (2014) Socio-Demographic Profile of Different Samples of Latin American Rural Extensionists. Ciência Rural, Santa Maria, 44, 575-581. http://dx.doi.org/10.1590/S0103-84782014000300030

[11] Philip, T.K. and Isaac, N.I. (2012) Demographic Characteristics, Agricultural and Technological Profile of Acha Farmers in Nigeria. Agricultural Engineering International: CIGR Journal, 14, 89-93.

[12] Rochecouste, Jean-F., Dargusch, P., Cameron, D. and Smith, C. (2015) An Analysis of the Socio-Economic Factors Influencing the Adoption of Conservation Agriculture as a Climate Change Mitigation Activity in Australian Dry-Land Grain Production. Agricultural Systems, 135, 20-30. http://dx.doi.org/10.1016/j.agsy.2014.12.002

[13] Yonazi, E., Kelly, T., Halewood, N. and Blackman, C. (2012) eTransform Africa: The Transformational Use of ICTs in Africa.

[14] Zhang, Y., Wang, L. and Duan, Y. (2016) Agricultural Information Dissemination Using ICTs: A Review and Analysis of Information Dissemination Models in China. Information Processing in Agriculture, 3, 17-29. http://dx.doi.org/10.1016/j.inpa.2015.11.002 